\title{
PET Imaging of the Natural Killer Cell Activation Receptor NKp30
}

\author{
Travis M. Shaffer ${ }^{1}$, Amin Aalipour ${ }^{2}$, Christian M. Schürch ${ }^{3}$, and Sanjiv S. Gambhir ${ }^{\dagger 1,2,4}$ \\ ${ }^{I}$ Department of Radiology, Stanford University, Stanford, California; ${ }^{2}$ Department of Bioengineering, Stanford University, Stanford, \\ California; ${ }^{3}$ Department of Microbiology and Immunology, Stanford University, Stanford, California; and ${ }^{4}$ Bio-X Program and \\ Molecular Imaging Program at Stanford, Stanford University, Stanford, California
}

Redirecting the immune system in cancer treatment has led to remarkable responses in a subset of patients. Natural killer (NK) cells are innate lymphoid cells being explored as they engage tumor cells in different mechanisms compared with T cells, which could be exploited for treatment of nonresponders to current immunotherapies. NK cell therapies are monitored through measuring peripheral NK cell concentrations or changes in tumor volume over time. The former does not detect NK cells at the tumor site, and the latter is inaccurate for immunotherapies because of pseudoprogression. Therefore, new imaging methods are required as companion diagnostics for optimizing immunotherapies. Methods: In this study, we developed and completed preclinical in vivo validation of 2 antibody-based PET probes specific for NKp30, an activation natural cytotoxicity receptor expressed by human NK cells. Quantitative, multicolor flow cytometry during a variety of NK cell activation conditions was completed on primary human NK cells and the NK92MI cell line. Human renal cell carcinoma (RCC) tumors were stained for the NK cell receptors CD56, $\mathrm{NKp30}$, and NKp46 to determine expression on tumor-infiltrating NK cells. An NKp30 antibody was radiolabeled with ${ }^{64} \mathrm{Cu}$ or ${ }^{89} \mathrm{Zr}$ and evaluated in subcutaneous xenografts and adoptive cell transfer mouse models. Results: Quantitative flow cytometry showed consistent expression of the NKp30 receptor during different activation conditions. NKp30 and NKp46 costained in RCC samples, demonstrating the expression of these receptors on tumor-infiltrating NK cells in human tumors, whereas tumor cells in one RCC sample expressed the peripheral NK marker CD56. Both PET tracers showed high stability and specificity in vitro and in vivo. Notably, ${ }^{89} \mathrm{Zr}-\mathrm{NKp} 30 \mathrm{Ab}$ had higher on-target contrast than ${ }^{64} \mathrm{Cu}-\mathrm{NKp} 30 \mathrm{Ab}$ at their respective terminal time points. ${ }^{64} \mathrm{Cu}-\mathrm{NKp} 30 \mathrm{Ab}$ delineated NK cell trafficking to the liver and spleen in an adoptive cell transfer model. Conclusion: The consistent expression of NKp3O on NK cells makes it an attractive target for quantitative imaging. Immunofluorescence staining on human RCC samples demonstrated the advantages of NKp30 targeting versus CD56 for detection of tumor infiltrating NK cells. This work advances PET imaging of NK cells and supports the translation of imaging agents for immunotherapy monitoring.

Received Jul. 9, 2019; revision accepted May 20, 2020.

For correspondence or reprints contact: Travis M. Shaffer, 318 Campus Dr., Room E150, Stanford, CA 94305.

E-mail address: tshaffer@stanford.edu

Sanjiv S. Gambhir, Clark Center, Stanford University, 318 Campus Dr., Room E150, Stanford, CA 94305.

E-mail: sgambhir@stanford.edu

tDeceased.

Published online Jun. 12, 2020.

COPYRIGHT (C 2020 by the Society of Nuclear Medicine and Molecular Imaging.
Key Words: natural killer; NK; NKp30; immune cell imaging; innate lymphoid cell; cancer immunotherapy

J Nucl Med 2020; 61:1348-1354

DOI: 10.2967/jnumed.119.233163

$\mathbf{R}$ edirecting the immune system to detect and destroy malignancies has resulted in remarkable responses in a subset of cancers $(1,2)$. However, the moderate success rates of these therapies, associated costs (often $>\$ 100,000 / y$ ) (3), and potential adverse side effects such as cytokine release syndrome (4) have led to exploration into new strategies to aid the immune system against cancer. One such strategy modulates natural killer (NK) cells, important innate lymphoid cells that are the first immunologic defenders against viral and cancer threats (5). NK cells kill target cells without the need for prior sensitization and interact with their environment via a complex integration of signals from an array of receptors. Because NK cells can detect the absence of major histocompatibility complex 1 , they can destroy cancer cells that escape detection by $\mathrm{T}$ cells through the downregulation of this receptor (6-9). They are also a main cell type responsible for antibody-dependent cellular cytotoxicity $(10,11)$.

Therapeutic strategies using NK cells include both adoptive cell transfer (ACT) and modulating NK response in situ (12). Therapeutic response is gauged using CT/MRI or analysis of circulating NK cells via flow cytometry (13). Measuring changes in tumor volume via CT/MRI has limited prognostic value for immunotherapies due to the influx of effector cells in the tumor microenvironment, leading to pseudoprogression. Likewise, circulating NK cell concentration is a poor surrogate for NK cell engagement and activation at desired sites of therapeutic action. New approaches are needed to noninvasively monitor NK cell localization and activation to better predict therapy responses, shed light on mechanisms of therapeutic failure, and facilitate the clinical translation of emerging NK cell cancer therapies.

For both allogeneic and autologous ACT therapies, a variety of methods are available for quantitative imaging through ex vivo labeling with ${ }^{111} \mathrm{In}$-oxine $(14),{ }^{89} \mathrm{Zr}$-oxine $(15,16)$, or PET reporter gene methods (17). However, there is currently a lack of endogenous NK cell imaging agents to use as companion diagnostics for therapies that modulate endogenous NK cells and can also be used with adoptive cell therapies (5). An ideal endogenous NK imaging biomarker is a receptor that is both highly and specifically expressed on activated cells. One study imaged the human CD56 receptor with 
a ${ }^{99 m}$ Tc-radiolabeled antibody for SPECT (18). However, CD56 is expressed on numerous cell types, including T cells, NK cells, dendritic cells, and monocytes, along with a subset of cancers, including glioma, renal cell carcinoma (RCC), and pancreatic cancer $(19,20)$, thus potentially precluding its use for specifically imaging tumorinfiltrating NK cells. Additionally, CD56 has a dim expression in NK cells with high cytotoxic activity and a high expression in NK cells that have an immunoregulatory role (21).

The natural cytotoxicity receptors are activation receptors specifically expressed on human NK cells (along with rare innate lymphoid subsets) (22,23). Among natural cytotoxicity receptors, activating ligands for NKp30 are the most widely known, such as the tumor ligand B7-H6. Intense NKp30 immunohistochemistry staining has been shown to be a positive response indicator of survival in a variety of cancers, including acute myeloid leukemia (24), gastric cancer (25), and cervical cancer (26). To establish the utility of NKp30 as an imaging biomarker, we performed quantitative flow cytometry on human NK cells to determine the number of natural cytotoxicity receptors available for imaging. We also stained for NKp30 expression in human tumor samples, and we developed 2 antibody-based PET tracers specific for NKp30 for in vivo imaging in both tumor xenografts and ACT models.

\section{MATERIALS AND METHODS}

\section{Human NK Cell Isolation and Culturing}

Human buffy coats were obtained from the Stanford blood bank. Peripheral blood mononuclear cells were isolated using a Sepmate-50 kit (StemCell Tech). Human NK cells were isolated from peripheral blood mononuclear cells using a negative selection magnetic bead kit specific for human NK cells (StemCell Tech). Cells were grown in 12well plates using NK MACS medium (Miltenyi) supplemented with human serum and IL-2 for $4 \mathrm{~d}$ before use. NK92MI and primary human NK cells were activated with the addition of NK activation beads (Miltenyi) at a 2:1 bead-to-cell ratio or with phorbol 12myristate 13 -acetate $(50 \mathrm{ng} / \mathrm{mL})$ and ionomycin $(0.5 \mu \mathrm{g} / \mathrm{mL})$. Flow cytometry was completed $24 \mathrm{~h}$ after activation.

\section{Flow Cytometry on NK Cells}

Quantitative flow cytometry on transfected HeLa cells was completed using a Qifikit (Agilent) per kit instructions with 1 alteration. An allophycocyanin $\mathrm{F}\left(\mathrm{ab}^{\prime}\right)$ 2-goat antimouse $\operatorname{IgG}$ (heavy and light chain) secondary antibody (Thermo Fisher) was used rather than the kit-provided fluorescein isothiocyanate secondary antibody because of the HeLa-NKp30 cell line expressing green fluorescent protein. NK92MI and primary NK cell receptors were quantified using kits from BangsLabs. Quantifying NKp30 receptors on NK92MI and primary human NK cells was completed using molecules-of-equivalent-soluble-fluorochrome calibration beads for phycoerythrin and allophycocyanin fluorophores. Cells were stained with 4',6-diamidino2-phenylindole, fluorescein isothiocyanate-CD3, phycoerythrin-NKp30Ab, allophycocyanin-NKp46Ab, and PerCp-Vio700 CD56 per manufacturer recommendations. Fc block (BD Biosciences) was used to prevent nonspecific antibody binding. Flow cytometry was completed using an LSR II instrument (BD Biosciences). Compensation beads, isotype controls, and fluorescence-minus-one technique were used for data analysis and gating. Data were analyzed using FlowJo (TreeStar).

\section{Immunofluorescence Staining}

Fresh-frozen RCC patients' samples embedded in optimal-cuttingtemperature medium (catalog number 25680-930; VWR/Sakura) were sectioned to a $7-\mu \mathrm{m}$ thickness on a cryostat (Leica), mounted onto glass cover slips $\left(22 \times 22 \mathrm{~mm}, \# 1 \frac{1 / 2}{2}\right.$ thickness, catalog number 72204-01; Electron Microscopy Sciences) precoated with poly-L-lysine (catalog number P8920-500ML; Sigma-Aldrich), air-dried, and stored at $-80^{\circ} \mathrm{C}$.
Staining buffers were prepared and procedures performed as previously described (27), with slight modifications. Briefly, tissues were recovered from $-80^{\circ} \mathrm{C}$ on drierite desiccant (catalog number 07-578-3A; Thermo Fisher) for $2 \mathrm{~min}$ at room temperature, followed by incubation in acetone for $10 \mathrm{~min}$. Tissues were then dried for $2 \mathrm{~min}$ in a humidity chamber, hydrated in staining solution 1 , and fixed in staining solution 1 containing 1.6\% paraformaldehyde (catalog number 50-980-487; Thermo Fisher) for $10 \mathrm{~min}$. After fixation, sections were washed in staining solution 1, followed by equilibration in staining solution 2. Nonspecific binding was blocked by incubating the sections in blocking buffer (mouse IgG, 50 $\mu \mathrm{g} / \mathrm{mL}$ [catalog number I5381; Sigma-Aldrich], and rat IgG, $50 \mu \mathrm{g} / \mathrm{mL}$ [catalog number I4131; Sigma-Aldrich], in staining solution 2) for $10 \mathrm{~min}$ at room temperature. The staining cocktail was prepared in blocking buffer using the following antibodies: mouse antihuman NKp46-AlexaFluor488 (dilution 1:50, catalog number 331937; Biolegend), mouse antihuman CD56-phycoerythrin (dilution 1:100, catalog number 362524; Biolegend), and mouse antihuman NKp30-allophycocyanin (dilution 1:20, catalog number FAB1849A-025; R\&D Systems). Sections were stained for $2 \mathrm{~h}$ at room temperature, washed in staining solution 2 for $5 \mathrm{~min}$, and fixed with $1.6 \%$ paraformaldehyde in staining solution 4 for $10 \mathrm{~min}$ at room temperature. Nuclei were counterstained with Hoechst 33342 (dilution 1:1,000, catalog number 62249; Thermo Fisher), and coverslips were mounted onto glass slides using Cytoseal xylene mounting medium (8312-4; Thermo Fisher). Hematoxylin- and eosin-stained sections were prepared using standard pathology procedures. Images were acquired on a BZ-X710 inverted fluorescence microscope (Keyence) equipped with a $\times 40$ plan fluorite oil objective and processed using ImageJ/Fiji.

\section{NK Cell Kill Assay}

MeWo or SK-Mel-28 human melanoma cells expressing firefly luciferase were seeded in 96-well plates at 10,000 cells per well. At $24 \mathrm{~h}$ after seeding, 10,000 NK92MI cells with or without the NKp30Ab were added to the wells, along with NKp30Ab alone and control wells with only tumor cells. NKp30Ab diluted in phosphate-buffered saline (PBS) was added at 10,000 or 100,000 antibodies per NK cell. Luciferase imaging was performed at $24 \mathrm{~h}$ after cell incubation to assess the killing capabilities of the NK92MI cell line using an IVIS system (Perkin Elmer) on addition of D-luciferin $(0.3 \mathrm{mg} / \mathrm{mL}$ final concentration $)$.

\section{Cell Culture and Transfection of NKp30 Receptor}

The human NK cell line NK92MI and HeLa human cervical carcinoma cells were obtained from American Type Culture Collection. NK92MI (human NK) cells were cultured in RPMI medium supplemented with $20 \%$ fetal bovine serum, $1 \%$ antibioticantimycotic, and $0.1 \mathrm{mM} 2$-mercaptoethanol. HeLa cells were cultured in Dulbecco modified Eagle medium supplemented with $10 \%$ fetal bovine serum and $1 \%$ antibiotic-antimycotic. A plasmid was obtained from VectorBuilder consisting of the human NKp30 (natural cytotoxicity receptor 3 ) sequence driven by the EF1 $\alpha$ promoter; enhanced green fluorescent protein and the puromycin-resistant gene were driven by the human cytomegalovirus immediate early enhancer for selection of stable cells (Supplemental Fig. 1A; supplemental materials are available at http://jnm.snmjournals.org). HeLa cells were transfected using a Lipofectamine 3000 kit (ThermoFisher). Transfected HeLa cells (HeLa-NKp30) were placed under selection with the addition of puromycin, $40 \mu \mathrm{g} / \mathrm{mL}$, and sorted 3 times with the top $2 \%$ of phycoerythrin-NKp30Ab-positive green fluorescent protein-positive cells collected to generate a stable line (Supplemental Fig. 1B). All cell culture reagents were obtained from ThermoFisher Scientific.

\section{DOTA and Desferrioxamine Conjugation to NKp30 Antibody}

A low-endotoxin, azide-free purified (clone P30-15) monoclonal mouse IgG1 antibody specific for the human NKp30 receptor (NKp30Ab) along with the corresponding mouse isotype control $(\operatorname{IgG} 1, \kappa$ isotype control 
clone MOPC-12) was purchased from Biolegend. The antibodies were buffer-exchanged into PBS, pH 8.5, and DOTA-NHS ester was added $(1 \mathrm{mg} / \mathrm{mL})$ at a molar ratio of $20: 1$ and incubated overnight at $4{ }^{\circ} \mathrm{C}$. The DOTA-NKp30Ab was purified using 50-kDa spin filtration with 3 washes in $0.1 \mathrm{M}$ ammonium acetate, $\mathrm{pH}$ 5. For desferrioxamine conjugation, NKp30Ab (1 mg/mL) was buffer-exchanged into PBS, $\mathrm{pH}$ 8.5 , followed by the addition of desferrioxamine-SCN at a $20: 1$ or 40:1 ratio. This solution was allowed to conjugate for $2 \mathrm{~h}$ at $37^{\circ} \mathrm{C}$ followed by $50-\mathrm{kD}$ spin filtration and washing 3 times in PBS, pH 7.3.

\section{Radiolabeling of NKp30Ab}

${ }^{64} \mathrm{CuCl}_{2}$ in $0.1 \mathrm{~N} \mathrm{HCl}$ was obtained from the University of Wisconsin with a specific activity of $17.76-162.8 \mathrm{GBq} / \mu \mathrm{mol}$. This was added to DOTA-NKp30Ab at a ratio of $0.37 \mathrm{MBq} / \mu \mathrm{g}$ and a final $\mathrm{pH}$ of 5 and incubated at $37^{\circ} \mathrm{C}$ for $30 \mathrm{~min}$. Afterward, $5 \mu \mathrm{L}$ of $50 \mathrm{mM}$ ethylenediaminetetraacetic acid were added for $10 \mathrm{~min}$ to scavenge free ${ }^{64} \mathrm{Cu}$. Purification was achieved by spin filtration and 3 washes at $25^{\circ} \mathrm{C}$, with final resuspension in saline. Instant thin-layer chromatography (iTLC) with $50 \mathrm{mM}$ citric acid as the mobile phase and size-exclusion highperfusion liquid chromatography were completed to validate purity and specific activity, respectively.

${ }^{89} \mathrm{Zr}$-oxalate was obtained from the University of Alabama at a specific activity of $59.2-103.6 \mathrm{GBq} / \mu \mathrm{mol}$. This was neutralized with $1.0 \mathrm{M}$ sodium carbonate and added to desferrioxamine-NKp30Ab at a ratio of $0.185 \mathrm{MBq} / \mu \mathrm{g}$ and then incubated at $37^{\circ} \mathrm{C}$ for $60 \mathrm{~min}$, followed by the addition of $5 \mu \mathrm{L}$ of $50 \mathrm{mM}$ ethylenediaminetetraacetic acid for removal of free ${ }^{89} \mathrm{Zr}$. Purification was achieved as described for DOTA-NKp30Ab. iTLC was completed on the crude and purified product with $50 \mathrm{mM}$ ethylenediaminetetraacetic acid as the mobile phase.

\section{In Vitro Immunoreactivity and Serum Stability Assays}

A $3.7-\mathrm{MBq}$ activity of ${ }^{64} \mathrm{Cu}-\mathrm{NKp} 30 \mathrm{Ab}$ or ${ }^{89} \mathrm{Zr}-\mathrm{NKp} 30 \mathrm{Ab}$ along with isotype controls in $10 \mu \mathrm{L}$ of saline was incubated in $100 \mu \mathrm{L}$ of mouse or human serum at $37^{\circ} \mathrm{C}$. Samples with a volume of $1 \mu \mathrm{L}$ $(n=5)$ were taken every $24 \mathrm{~h}$ for iTLC. Immunoreactivity assays for ${ }^{64} \mathrm{Cu}-\mathrm{NKp} 30 \mathrm{Ab}$ and ${ }^{89} \mathrm{Zr}-\mathrm{NKp} 30 \mathrm{Ab}$ were completed as previously described (28). A $0.037-\mathrm{MBq}$ activity of the tracer was added to a serial dilution of $\mathrm{NKp} 30$-expressing $\mathrm{HeLa}$ cells, incubated for $30 \mathrm{~min}$, and washed twice in PBS before $\gamma$-counting. To assess specificity for human NK cells, $5 \times 10^{5} \mathrm{NK} 92 \mathrm{MI}$ or human NK cells were incubated with each tracer or isotype control and processed as above.

\section{In Vivo Xenograft Imaging and Biodistribution Studies}

Female $n u / n u$ mice were supplied by Charles River. When they were $6-10$ wk old, $5 \times 10^{5} \mathrm{NKp} 30$-expressing HeLa cells were mixed with $100 \mu \mathrm{L}$ of Matrigel (Corning) and injected into the left flank subcutaneously, whereas in the right flank an equivalent number of NKp30-negative HeLa cells mixed with Matrigel was injected. Xenografts were allowed to grow for $10-14 \mathrm{~d}$ before the PET studies. A 2.96- to 4.44-MBq activity (10-15 $\mu \mathrm{g})$ of ${ }^{64} \mathrm{Cu}-\mathrm{NKp} 30 \mathrm{Ab}$ or $1.85-3.7 \mathrm{MBq}(10$ $20 \mu \mathrm{g}$ ) of ${ }^{89} \mathrm{Zr}-\mathrm{NKp} 30 \mathrm{Ab}$ were injected intravenously in $100 \mu \mathrm{L}$ of saline via the tail vein at 2:00 to 6:00 PM. PET imaging was conducted every $24 \mathrm{~h}$ until $48 \mathrm{~h}$ for ${ }^{64} \mathrm{Cu}$ NKp30Ab or until $120 \mathrm{~h}$ for ${ }^{89} \mathrm{Zr}-\mathrm{NKp} 30 \mathrm{Ab}$. The mice were anesthetized using $2.5 \%$ isoflurane delivered in $100 \%$ oxygen for imaging. PET/CT scans were completed on an Inveon PET/CT device with scan times of $10 \mathrm{~min}$ for the 24-h time point and 20$30 \mathrm{~min}$ for subsequent time points. PET/CT images were reconstructed using Inveon software with attenuation correction applied. Experiments were completed on 2 separate occasions ( $n=3-4$ per run). All experiments were approved by the Stanford Administrative Panel on Laboratory Animal Care (approval 32843). A paired $t$ test was used to compare the statistical differences in tracer update in NKp30-positive and -negative tumor xenografts. A power calculation was completed with $90 \%$ power, $\alpha=0.05$, and assuming normal distribution to determine the number of mice per cohort.

\section{In Vivo NK92MI Imaging and \\ Biodistribution Studies}

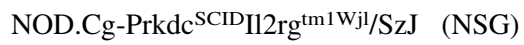
female mice were purchased from Charles River. When the mice were 6 wk old, they were injected intravenously with 500,000 NK92MI cells $(n=7)$. A $2.96-$ to $4.44-$ MBq activity $(10-15 \mu \mathrm{g})$ of ${ }^{64} \mathrm{Cu}-\mathrm{NKp} 30 \mathrm{Ab}(n=$ 4) or ${ }^{64} \mathrm{Cu}-\mathrm{IgG}(n=3)$ was injected $48 \mathrm{~h}$

FIGURE 1. Flow cytometry on primary human NK cells. (A) Gating strategy to delineate human NK cells isolated from human buffy coats. (B) Quantification of NKp30 receptor on primary human NK samples, NK92MI human NK cell line, and transfected HeLa/NKp30 line ( $n=3$ per condition, mean and SD are shown). Primary NK cells were activated for $24 \mathrm{~h}$ with activation beads or phorbol 12-myristate 13-acetate/ionomycin. APC = allophycocyanin; DAPI = 4',6-diamidino-2-phenylindole FITC = fluorescein isothiocyanate; PMAIIONO = phorbol myristate acetate/ionomycin; 


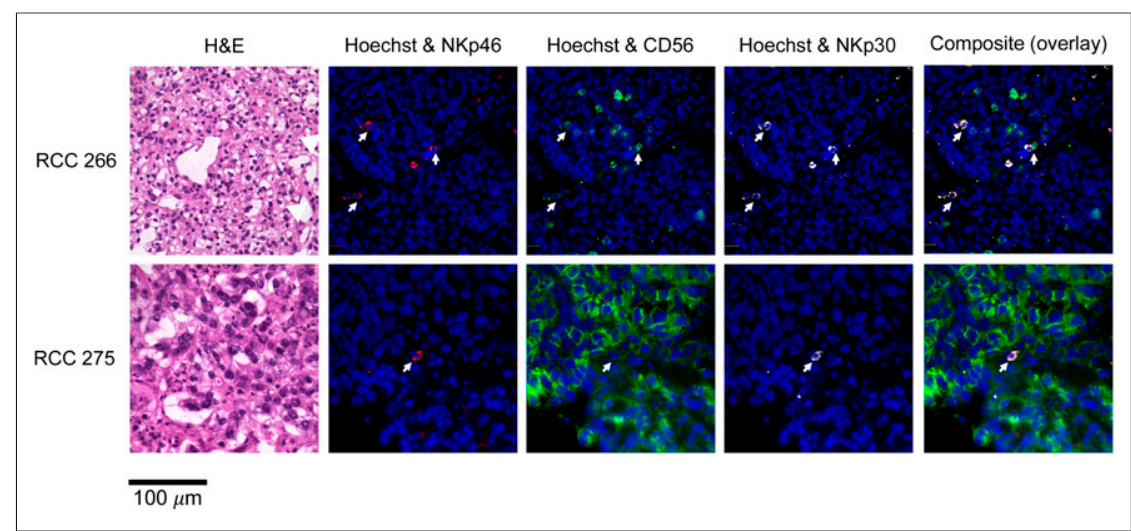

FIGURE 2. Detection of infiltrating human NK cells expressing NKp30 in RCC samples. RCC samples were stained with Hoechst 33342, AF488-NKp46, phycoerythrin-CD56, and allophycocyaninNKp30. Both samples had infiltrating NK cells that costained for NKp46 and NKp30, denoted by arrows. Tumor cells in RCC 275 were also positive for CD56, demonstrating limitation in specificity of this common marker for detection of peripheral NK cell staining. H\&E = hematoxylin and eosin.

after NK92MI cell injection. PET/CT imaging and ex vivo biodistribution were completed $48 \mathrm{~h}$ after PET tracer injection.

\section{RESULTS}

\section{Flow Cytometry and Kill Assays}

NK cells isolated from human buffy coats were more than $95 \%$ CD3-negative and expressed both NKp30 and NKp46 (Fig. 1A).
Primary NK cell NKp30 expression $(3,100 \pm$ 1,400 epitopes per cell) was not significantly altered during bead activation $(2,140 \pm$ 1,060 epitopes per cell) or via phorbol 12myristate 13 -acetate/ionomycin $(3,300 \pm$ 1,200 epitopes per cell) after $24 \mathrm{~h}$ (Fig. 1B). These results align with previous work in which approximately 2,000 NKp30 epitopes were detected per primary human NK cell (29). The NK92MI cell line had $25,500 \pm 1,750$ epitopes per cell, whereas the HeLa NKp30 line had 30,700 \pm 4,200 epitopes per cell (Fig. 1B). NKp30Ab had no effect on the ability of NK92MI cells to kill the human melanoma lines MeWo and SKMel-28 (Supplemental Fig. 2), matching previous results with $\mathrm{NKp} 30 \mathrm{Ab}(30)$.

\section{Immunofluorescence Staining of \\ CD56, NKp30, and NKp46}

With NKp30 expression validated on primary peripheral human NK cells, detecting NKp30 on tumorinfiltrating NK cells is essential for eventual translation. As flow cytometry on peripheral $\mathrm{NK}$ cells is defined as CD3-negative CD56-positive, CD56 was included in the immunofluorescence panel. Both RCC patient samples showed colocalization of NKp30 and NKp46 on infiltrating NK cells (Fig. 2). In RCC 275, tumor cells were also positive for CD56.

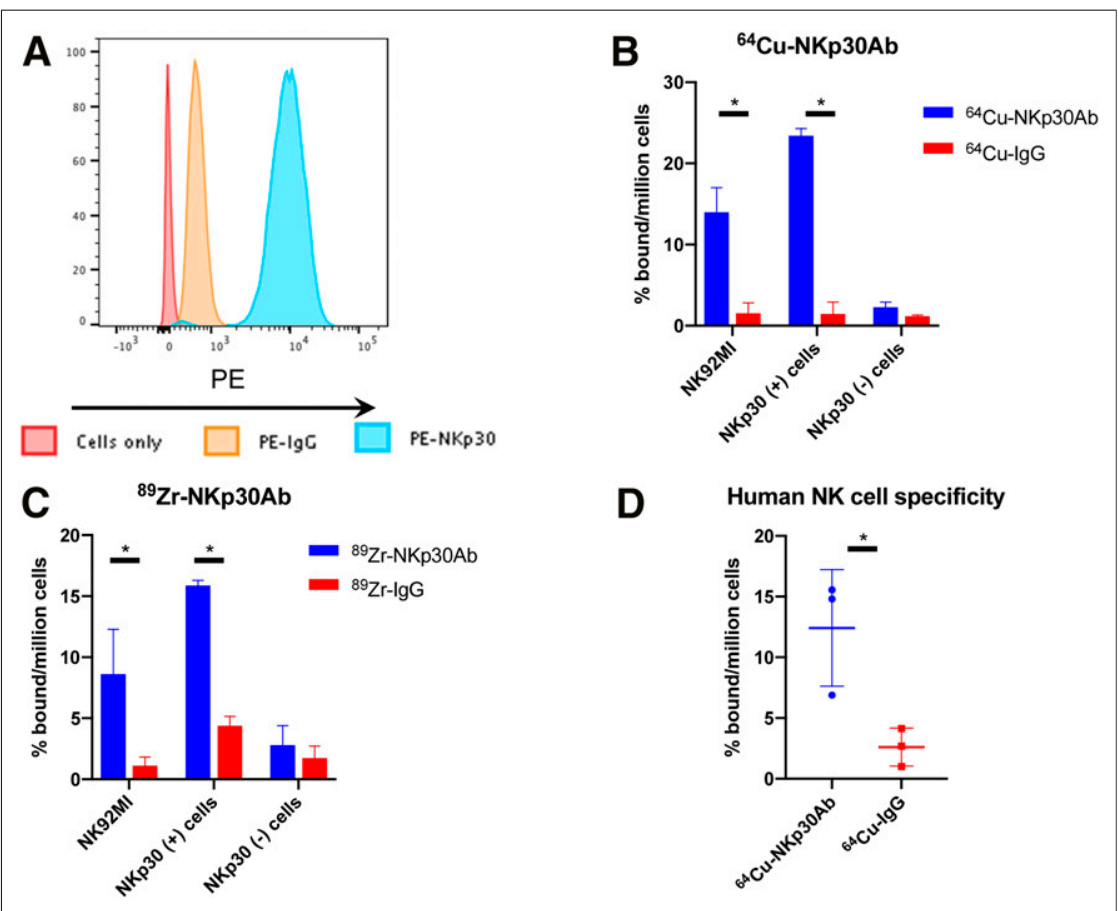

FIGURE 3. In vitro specificity for ${ }^{64} \mathrm{Cu}-\mathrm{NKp} 30 \mathrm{Ab}$ and ${ }^{89} \mathrm{Zr}$-NKp30Ab. (A) Flow cytometry of NKp30-expressing HeLa cells. (B) ${ }^{64} \mathrm{Cu}-\mathrm{NKp} 30 \mathrm{Ab}$ showing high specificity for Hela cells expressing NKp30 receptor and NK92MI human NK cell line, in comparison with NKp30-negative cell lines and isotype controls $(n=3)$. (C) ${ }^{89} \mathrm{Zr}-\mathrm{NKp} 30 \mathrm{Ab}$ showing high specificity for Hela cells expressing NKp30 receptor and NK92MI human NK cell line, in comparison with NKp30-negative cell lines and isotype controls $(n=3)$. (D) ${ }^{64} \mathrm{Cu}$-NKp30Ab showing specific uptake at 30 min after incubation in isolated and ex vivo activated human NK cells isolated from buffy coats, compared with isotype control $(n=3) .{ }^{*} P<0.05$. PE $=$ phycoerythrin.

\section{Radiolabeling NKp30Ab}

DOTA conjugation resulted in an average of 1.79 DOTA molecules per antibody, whereas desferrioxamine conjugation resulted in an average of 1.59 desferrioxamine molecules per antibody (Supplemental Figs. 3A3D). ${ }^{64} \mathrm{Cu}$ radiolabeling was achieved with a decay-corrected radiochemical yield of $60 \%-75 \%$ and completed more than 5 times. Purification resulted in radiochemical purity of more than $98 \%$ by iTLC and high-perfusion liquid chromatography and a specific activity of $0.185-0.37 \mathrm{MBq} / \mu \mathrm{g}$ (Supplemental Fig. 4A). ${ }^{64} \mathrm{Cu}-\mathrm{NKp} 30 \mathrm{Ab}$ was more than $95 \%$ stable in mouse and human serum up to $48 \mathrm{~h}$ at $37^{\circ} \mathrm{C}$ (Supplemental Fig. $4 \mathrm{~B}$ ). ${ }^{89} \mathrm{Zr}$ radiolabeling was achieved with a decay-corrected radiochemical yield of $80 \%-95 \%$ and completed more than 5 times. Radiochemical purity of more than $98 \%$ was achieved by iTLC, with a specific activity of $0.074-0.185$ $\mathrm{MBq} / \mu \mathrm{g}$ (Supplemental Fig. 4C). ${ }^{89} \mathrm{Zr}-$ $\mathrm{NKp} 30 \mathrm{Ab}$ and isotype controls were more than $95 \%$ stable in mouse and human serum up to $120 \mathrm{~h}$ at $37^{\circ} \mathrm{C}$ (Supplemental Figs. 4D-4E).

\section{PET Tracer In Vitro Binding Assays}

${ }^{64} \mathrm{Cu}-\mathrm{NKp} 30 \mathrm{Ab}$ and ${ }^{89} \mathrm{Zr}$-NKp30Ab showed specific binding in HeLa NKp30 cells (Fig. $3 \mathrm{~A}$ ), compared with both negative cells and isotype controls. Immunoreactivities of $72.3 \%$ 
for ${ }^{64} \mathrm{Cu}-\mathrm{NKp} 30 \mathrm{Ab}$ and $63.8 \%$ for ${ }^{89} \mathrm{Zr}-\mathrm{NKp} 30 \mathrm{Ab}$ were achieved (Supplemental Figs. 5A-5B). ${ }^{64} \mathrm{Cu}-\mathrm{NKp} 30 \mathrm{Ab}$ was further validated in both the human NK cell line NK92MI and human NK cells isolated from buffy coats and demonstrated specific in vitro binding $\left(P<0.05\right.$ relative to isotype control). Similarly, ${ }^{89} \mathrm{Zr}-$ NKp30Ab showed highly specific uptake in NKp30-expressing HeLa cells, compared with NKp30-negative lines and the ${ }^{89} \mathrm{Zr}-$ IgG controls (Figs. 3B-3D).

\section{In Vivo PET and Ex Vivo Biodistribution Studies}

${ }^{64} \mathrm{Cu}-\mathrm{NKp} 30 \mathrm{Ab} \mathrm{PET} / \mathrm{CT}$ and biodistribution results demonstrated specific uptake in NKp30-expressing Hela tumor xenografts, compared with wild-type HeLa cells and isotype controls (Figs. 4A and 4B). Ex vivo biodistribution for ${ }^{64} \mathrm{Cu}-\mathrm{NKp} 30 \mathrm{Ab}$ in NKp30-expressing xenografts was $15.2 \pm 4.5$ percentage injected dose per gram $(\% \mathrm{ID} / \mathrm{g})$, compared with $5.8 \pm 1.9 \% \mathrm{ID} / \mathrm{g}$ for the ${ }^{64} \mathrm{Cu}$-IgG control $(P<0.05) .{ }^{64} \mathrm{Cu}-\mathrm{NKp} 30 \mathrm{Ab}$ in the blood was 8.3 $\% \mathrm{ID} / \mathrm{g}$, as expected for a full-size monoclonal antibody.

${ }^{89} \mathrm{Zr}-\mathrm{NKp} 30 \mathrm{Ab} \mathrm{PET} / \mathrm{CT}$ and biodistribution results also demonstrated specific uptake in NKp30-expressing xenografts, compared with wild-type HeLa cells and isotype controls (Fig. 5A-B). At $120 \mathrm{~h}$, ex vivo biodistribution for ${ }^{89} \mathrm{Zr}-\mathrm{NKp} 30 \mathrm{Ab}$ in $\mathrm{NKp} 30$ expressing xenografts was $18.2 \pm 4.8 \% \mathrm{ID} / \mathrm{g}$, compared with $8.6 \pm 2.1 \% \mathrm{ID} / \mathrm{g}$ for the ${ }^{89} \mathrm{Zr}-\mathrm{IgG}$ control $(P<0.05)$. Tracer in the blood was $3.8 \% \mathrm{ID} / \mathrm{g}$, expected for a full-size antibody. At $48 \mathrm{~h}$ after injection, ${ }^{64} \mathrm{Cu}-\mathrm{NKp} 30 \mathrm{Ab}$ had tumor-to-blood and tumor-to-muscle ratios of $1.92 \pm 0.63$ and $9.84 \pm 6.1$, respectively, whereas at $120 \mathrm{~h}$ after injection, ${ }^{89} \mathrm{Zr}-\mathrm{NKp} 30 \mathrm{Ab}$ had tumor-to-blood and tumor-to-muscle ratios of $4.84 \pm 0.87$ and 19.72 \pm 5.77, respectively (Supplemental Fig. 6). The maximum pixel ratios for ${ }^{64} \mathrm{Cu}-\mathrm{NKp} 30 \mathrm{Ab} /{ }^{64} \mathrm{Cu}-\mathrm{IgG},{ }^{89} \mathrm{Zr}-\mathrm{NKp} 30 \mathrm{Ab} /{ }^{89} \mathrm{Zr}-\mathrm{IgG}$, and
NKp30 positive/negative xenografts are reported in Supplemental Table 1.

To evaluate this tracer for imaging human NK cells in vivo, an ACT model was developed with NSG mice injected with NK92MI cells. In ACT mice at $48 \mathrm{~h}$ after injection, NSG mice injected with ${ }^{64} \mathrm{Cu}-$ NKp30Ab showed increased uptake $(14.9 \pm 3.2 \% \mathrm{ID} / \mathrm{g}$ vs. $7.1 \pm 1.9$ $\% \mathrm{ID} / \mathrm{g})$ in the spleen $(P<0.05)$, and to a lesser extent the liver $(10.5 \pm$ $0.8 \% \mathrm{ID} / \mathrm{g}$ vs. $8.0 \pm 0.8 \% \mathrm{ID} / \mathrm{g})$, compared with ${ }^{64} \mathrm{Cu}-\mathrm{IgG}$. In contrast, blood activity was lower for ${ }^{64} \mathrm{Cu}-\mathrm{NKp} 30 \mathrm{Ab}$ than for ${ }^{64} \mathrm{Cu}-\mathrm{IgG}(11.6 \pm$ $0.7 \% \mathrm{ID} / \mathrm{g}$ vs. $15.7 \pm 1.5 \% \mathrm{ID} / \mathrm{g}$ ), likely because of increased ${ }^{64} \mathrm{Cu}-$ $\mathrm{NKp} 30 \mathrm{Ab}$ uptake in the liver and spleen. No other organs exhibited significant differences in ${ }^{64} \mathrm{Cu}$ uptake (Figs. 6A and 6B).

\section{DISCUSSION}

NK cells are a critical component of the immune system, especially in defense from viral and cancer threats. Molecular imaging has played a limited role to date in both preclinical and clinical studies of NK cells since they rely on ex vivo loading of imaging agents such as fluorescent dyes $(31,32)$, MR contrast, SPECT tracers $(14,33)$, or PET tracers $(34,35)$ into NK cells. However, these approaches are not applicable to imaging endogenous NK cells in their native environment and also suffer from signal dilution due to cell division and death. Other methods such as PET reporter genes (17) have yet to be explored for NK cells and are limited to cells expanded and activated ex vivo.

The number of NKp30 epitopes per cell $(2,000-4,000)$ indicates that NKp30 expression does not significantly vary after $24 \mathrm{~h}$ of activation in primary NK cells and the NK92MI cell line, making it a good general marker for NK cells. HeLa cells engineered to express NKp30 had NKp30 receptor levels similar to those of the NK92MI cell line, making it a realistic model for determining in vitro binding.

Although the quantitative flow cytometry data demonstrated that the receptor is expressed at levels desirable as an imaging biomarker, detecting NKp30 on tumor-infiltrating NK cells was necessary because this is one of the desired clinical applications. Immunofluorescence on human RCC samples showed NKp30 and NKp46 colocalization in infiltrating NK cells, demonstrating that tumor-infiltrating NK cells express the target of interest. This experiment also highlighted a major limitation of using the NK marker CD56-tumors such as glioma and RCC can express this marker (20), precluding specific quantification of $\mathrm{NK}$ cell infiltration.

With NKp30 validated as an NK cellspecific marker expressed on tumor-infiltrating NK cells, an anti-NKp30 full-size antibody was radiolabeled and characterized. Both PET tracers demonstrated high specificity for NKp30-expressing HeLa cells, the human NK92MI cell line, and human NK cells isolated from buffy coats. ${ }^{64} \mathrm{Cu}$ and ${ }^{89} \mathrm{Zr}-\mathrm{NKp} 30 \mathrm{Ab}$ demonstrated specificity and expected pharmacokinetics $(36,37)$ in in vivo murine xenografts. Although the longer half-life of ${ }^{89} \mathrm{Zr}(78.4 \mathrm{~h})$ aligns better
FIGURE 4. In vivo ${ }^{64} \mathrm{Cu}-\mathrm{NKp} 30 \mathrm{Ab} \mathrm{PET} / \mathrm{CT}$ imaging of NKp30 expression in tumor xenografts and ex vivo biodistribution study. (A) ${ }^{64} \mathrm{Cu}-\mathrm{NKp30Ab}$ and ${ }^{64} \mathrm{Cu}$-lgG PET/CT imaging completed at 24 and $48 \mathrm{~h}$ after injection ( $n=10,3$ separate cohorts). Left flank has NKp30-expressing HeLa cell xenografts $(+$, white dotted circle), whereas right flank has wild-type HeLa cell xenografts without NKp30 expression (-, orange dashed circle). (B) Biodistribution of ${ }^{64} \mathrm{Cu}-\mathrm{NKp} 30 \mathrm{Ab}$ and ${ }^{64} \mathrm{Cu}-\mathrm{IgG}$ at $48 \mathrm{~h}$ after injection ( $n=10,3$ separate cohorts). ${ }^{*} P<0.05$; mean and SD are shown. 


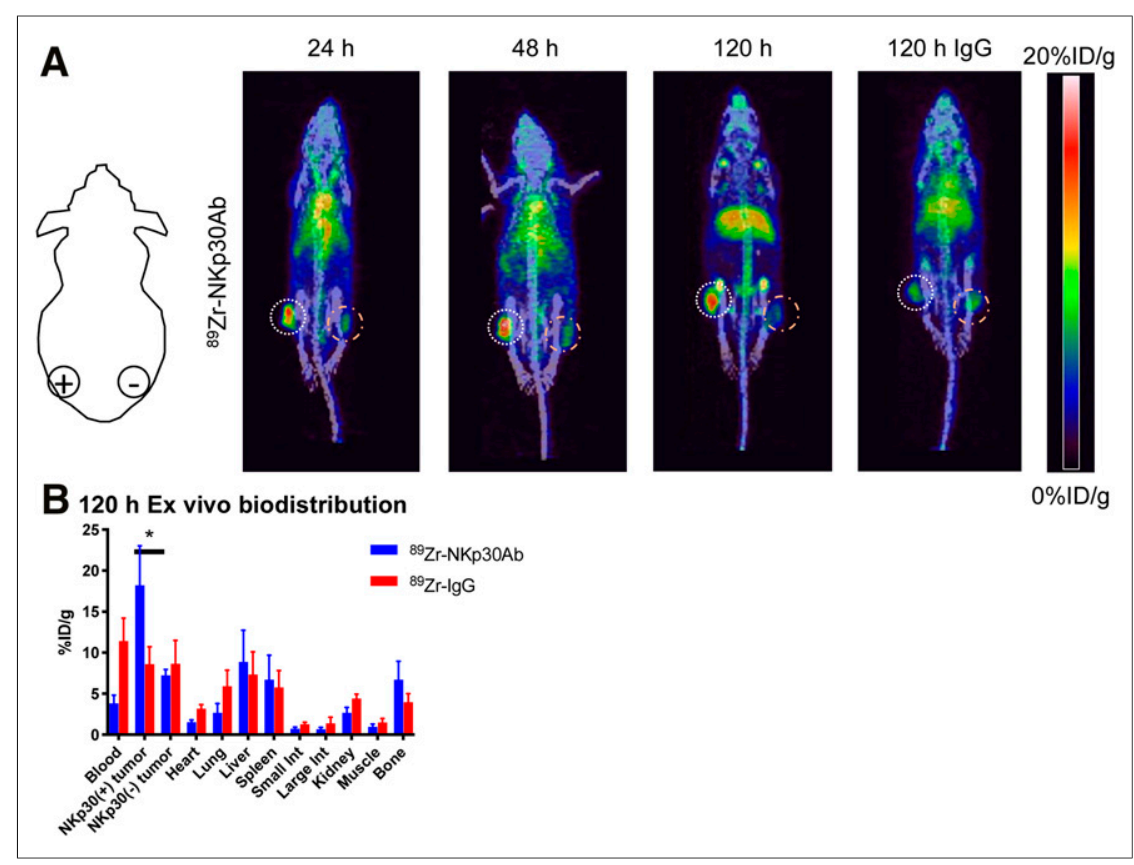

FIGURE 5. In vivo ${ }^{89} \mathrm{Zr}$-NKp30Ab PET/CT imaging of NKp30 expression in tumor xenografts and ex vivo biodistribution study. (A) ${ }^{89} \mathrm{Zr}-\mathrm{NKp} 30 \mathrm{Ab}$ imaging at 24,48 , and $120 \mathrm{~h}$ after injection $(n=7) .{ }^{89} \mathrm{Zr}$ IgG PET/CT imaging at $120 \mathrm{~h}$ after injection is shown as comparison $(n=7)$. Left flank has NKp30expressing HeLa cell xenografts (+, white dotted circle), whereas right flank has wild-type HeLa cell xenografts without NKp30 expression (-, orange dashed circle). (B) Biodistribution of ${ }^{89} \mathrm{Zr}-\mathrm{NKp} 30 \mathrm{Ab}$ and ${ }^{89} \mathrm{Zr}$-lgG at $120 \mathrm{~h}$ after injection $\left(n=7,2\right.$ separate cohorts). ${ }^{*} P<0.05$; mean and SD are shown. investigate this possibility, the effect of the NKp30Ab on NK cells' ability to kill melanoma cells was tested in vitro and had no deleterious effect. This finding aligns with previous reports that multiple activating receptors need to be simultaneously engaged to surpass the activation threshold (40).

Although this study develops and validates PET imaging tools for NK cells, there are limitations to address in future studies. Since NKp30 is not expressed by murine NK cells, a murine version of this probe could not be assessed in immunocompetent mice. To address this issue, NK cells were injected into NSG mice followed by the NKp30Ab PET probe, which demonstrated the ability to quantitatively image these cells. Xenografts of transfected HeLa cells expressing NKp30 in $n u / n u$ mice were used and had a concentration of cell-surface NKp30 receptors that was similar to that of the NK92MI cell line but was a log order higher than that of primary NK cells. Although the low number of NK cells that typically infiltrate tumors is a potential challenge (41), the immunofluorescence presented here demonstrate that tumor-infiltrating NK cells do express NKp30. Future work testing this with antibodies than the half-life of ${ }^{64} \mathrm{Cu}(12.7 \mathrm{~h})$, both have been translated for antibody PET imaging and therefore were evaluated here.

Even with the aforementioned pharmacokinetic limitations, ${ }^{64} \mathrm{Cu}-$ NKp30Ab was able to image ACT in an NSG model, with injected NK cells (NK92MI) residing in the spleen and liver quantified at $48 \mathrm{~h}$ after injection. NK cells in immunodeficient mice home to the spleen, matching previous results $(38,39)$. These results demonstrate that the PET probe can image the migrating of human NK cells in vivo, an essential prerequisite for potential translation. To further

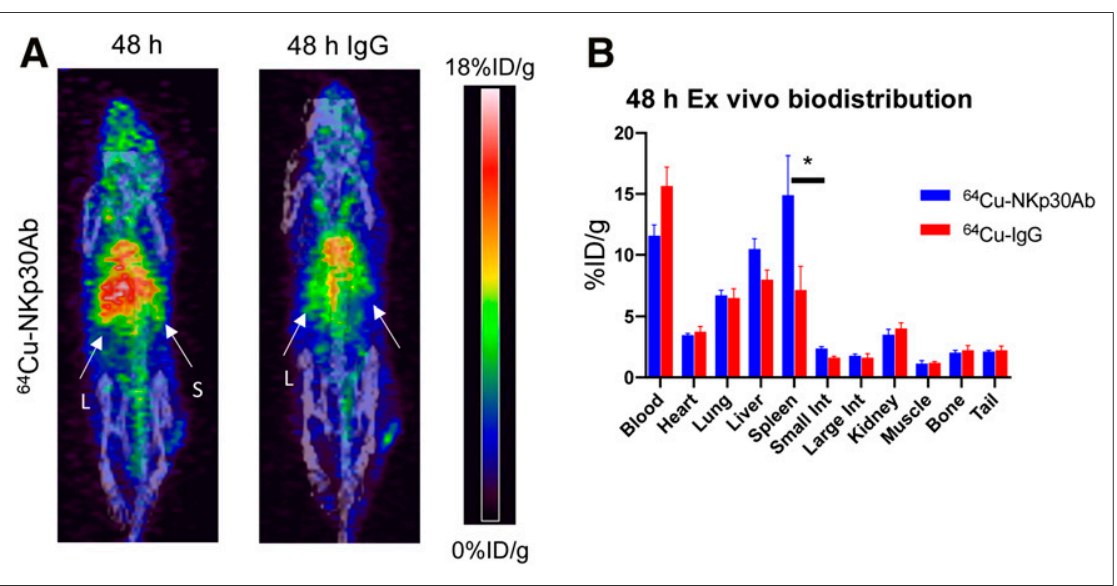

FIGURE 6. In vivo ${ }^{64} \mathrm{Cu}-\mathrm{NKp} 30 \mathrm{Ab}$ immuno-PET and ex vivo biodistribution study in ACT model of NK cells injected intravenously in NSG mice. (A) ${ }^{64} \mathrm{Cu}-\mathrm{NKp} 30 \mathrm{Ab}$ and ${ }^{64} \mathrm{Cu}-\mathrm{IgG}$ PET/CT imaging completed at $48 \mathrm{~h}$ after injection $(n=3-4)$. Higher liver and spleen uptake is seen for ${ }^{64} \mathrm{Cu}-\mathrm{NKp30Ab}$ than for ${ }^{64} \mathrm{Cu}-\mathrm{lgG}$ because of presence of NK92MI cells. (B) Biodistribution of ${ }^{64} \mathrm{Cu}-\mathrm{NKp30Ab}$ and ${ }^{64} \mathrm{Cu}-\operatorname{lgG}$ at $48 \mathrm{~h}$ after injection $(n=3-4) .{ }^{*} P<0.05$; mean and SD are shown. $\mathrm{L}=$ liver; $\mathrm{S}=$ spleen.
PET imaging probe in tumor-bearing, humanized immune models will elucidate levels of sensitivity and the ability to predict and monitor therapeutic response to immune-targeting therapies.

\section{CONCLUSION}

The current work quantified NK cell receptors in primary human NK cells and NK cell lines used in clinical trials and detected the presence of NKp30-expressing, tumor-infiltrating NK cells in human cancer patients. NKp30 PET tracers labeled with ${ }^{64} \mathrm{Cu}$ or ${ }^{89} \mathrm{Zr}$ both demonstrated specificity in vivo, with ${ }^{89} \mathrm{Zr}$ $\mathrm{NKp30Ab}$ exhibiting superior in vivo contrast at their respective optimal time points. The distribution of NK cells in an ACT mouse model was quantified using ${ }^{64} \mathrm{Cu}$ NKp30Ab. Our data support continued development of NK cell-specific PET tracers for imaging response during NK cell therapies that are currently being investigated in the clinic.

\section{DISCLOSURE}

This work was supported by a CancerTranslational Nanotechnology Training grant (T32 CA196585 to Travis Shaffer), a Swiss National Science Foundation Postdoc Mobility Fellowship (P400PM_183915 to Christian Schürch), the Ben and Catherine Ivy Foundation (Sanjiv Gambhir), the Canary Foundation (Sanjiv Gambhir), National 
Institutes of Health (NIH) National Cancer Institute (NCI) U01 Grant CA188383 (Sanjiv Gambhir), and a Stanford Bio-X seed grant (Sanjiv Gambhir). No other potential conflict of interest relevant to this article was reported.

\section{ACKNOWLEDGMENTS}

Small-animal PET/CT imaging and $\gamma$-counter measurements were performed at the Stanford Center for In Vivo Imaging $\left(\mathrm{SCi}^{3}\right)$. We thank Sarah Black for performing immunofluorescence staining of RCC samples. The coauthors would like to dedicate this work to Dr. Sanjiv Sam Gambhir (1962-2020) for his excellent mentoring and tremendous support through the years.

\section{KEY POINTS}

QUESTION: Is NKp30 a valid PET imaging biomarker for human NK cells?

PERTINENT FINDINGS: NKp30 had consistent expression on human NK cells from various donors and is expressed on tumorinfiltrating NK cells in human RCC. Although both ${ }^{64} \mathrm{Cu}$ - and ${ }^{89} \mathrm{Zr}$ NKp30Ab PET probes had high stability, specificity, and immunoreactivity, ${ }^{89} \mathrm{Zr}$-NKp30Ab showed statistically significant target-to-background PET signals at optimal imaging time points. ${ }^{64} \mathrm{Cu}-\mathrm{NKp} 30 \mathrm{Ab}$ demonstrated the ability to image ACT of NK cells in NSG mice.

IMPLICATIONS FOR PATIENT CARE: Our NK cell PET diagnostic probes have the potential for measuring in vivo NK tumor infiltration in upcoming therapeutic NK cell trials.

\section{REFERENCES}

1. Yang Y. Cancer immunotherapy: Harnessing the immune system to battle cancer. J Clin Invest. 2015;125:3335-3337.

2. Wolchok JD, Chiarion-Sileni V, Gonzalez R, et al. Overall survival with combined nivolumab and ipilimumab in advanced melanoma. $N$ Engl $\mathrm{J}$ Med. 2017;377:1345-1356.

3. Dusetzina SB. Drug pricing trends for orally administered anticancer medications reimbursed by commercial health plans, 2000-2014. JAMA Oncol. 2016;2:960-961.

4. Postow MA, Sidlow R, Hellmann MD. Immune-related adverse events associated with immune checkpoint blockade. N Engl J Med. 2018;378:158-168.

5. Shapovalova M, Pyper SR, Moriarity BS, LeBeau AM. The molecular imaging of natural killer cells. Mol Imaging. 2018;17:1536012118794816.

6. Rezvani K, Rouce R, Liu E, Shpall E. Engineering natural killer cells for cancer immunotherapy. Mol Ther. 2017;25:1769-1781.

7. Muntasell A, Ochoa MC, Cordeiro L, et al. Targeting nk-cell checkpoints for cancer immunotherapy. Curr Opin Immunol. 2017;45:73-81.

8. Guillerey C, Huntington ND, Smyth MJ. Targeting natural killer cells in cancer immunotherapy. Nat Immunol. 2016;17:1025-1036.

9. Fehniger TA, Cooper MA. Harnessing NK cell memory for cancer immunotherapy. Trends Immunol. 2016;37:877-888.

10. López-Soto A, Gonzalez S, Smyth MJ, Galluzzi L. Control of metastasis by NK cells. Cancer Cell. 2017;32:135-154.

11. Ochoa MC, Minute L, Rodriguez I, et al. Antibody-dependent cell cytotoxicity: Immunotherapy strategies enhancing effector NK cells. Immunol Cell Biol. 2017;95:347-355.

12. Klingemann H. Challenges of cancer therapy with natural killer cells. Cytotherapy. 2015;17:245-249.

13. Krasnova Y, Putz EM, Smyth MJ, Souza-Fonseca-Guimaraes F. Bench to bedside: NK cells and control of metastasis. Clin Immunol. 2017;177:50-59.

14. Meller B, Frohn C, Brand JM, et al. Monitoring of a new approach of immunotherapy with allogenic ${ }^{111}$ In-labelled NK cells in patients with renal cell carcinoma. Eur J Nucl Med Mol Imaging. 2004;31:403-407.

15. Levy E, Reger R, Segerberg F, et al. Enhanced bone marrow homing of natural killer cells following mRNA transfection with gain-of-function variant CXCR4(R334x). Front Immunol. 2019;10:1262.
16. Sato N, Wu H, Asiedu KO, Szajek LP, Griffiths GL, Choyke PL. ${ }^{89} \mathrm{Zr}$-oxine complex PET cell imaging in monitoring cell-based therapies. Radiology. 2015;275:490-500.

17. Keu KV, Witney TH, Yaghoubi S, et al. Reporter gene imaging of targeted T cell immunotherapy in recurrent glioma. Sci Transl Med. 2017;9:eaag2196.

18. Galli F, Rapisarda AS, Stabile H, et al. In vivo imaging of natural killer cell trafficking in tumors. $J$ Nucl Med. 2015;56:1575-1580.

19. Uhlén M, Fagerberg L, Hallstrom BM, et al. Proteomics: tissue-based map of the human proteome. Science. 2015;347:1260419.

20. The Human Protein Atlas website. https://www.proteinatlas.org/. Updated March 6, 2020. Accessed July 17, 2020.

21. De Maria A, Bozzano F, Cantoni C, Moretta L. Revisiting human natural killer cell subset function revealed cytolytic CD56(dim)CD16+ Nk cells as rapid producers of abundant IFN-gamma on activation. Proc Natl Acad Sci USA. 2011;108:728-732.

22. Kruse PH, Matta J, Ugolini S, Vivier E. Natural cytotoxicity receptors and their ligands. Immunol Cell Biol. 2014;92:221-229.

23. Li Y, Mariuzza RA. Structural basis for recognition of cellular and viral ligands by NK cell receptors. Front Immunol. 2014;5:123.

24. Chretien AS, Fauriat C, Orlanducci F, et al. NKp30 expression is a prognostic immune biomarker for stratification of patients with intermediate-risk acute myeloid leukemia. Oncotarget. 2017;8:49548-49563.

25. Han B, Mao FY, Zhao YL, et al. Altered NKp30, NKp46, NKG2D, and DNAM-1 expression on circulating NK cells is associated with tumor progression in human gastric cancer. J Immunol Res. 2018;2018:6248590.

26. Garcia-Iglesias T, Del Toro-Arreola A, Albarran-Somoza B, et al. Low NKp30, NKp46 and NKG2D expression and reduced cytotoxic activity on nk cells in cervical cancer and precursor lesions. BMC Cancer. 2009;9:186.

27. Schürch CM, Bhate SS, Barlow GL, et al. Coordinated cellular neighborhoods orchestrate antitumoral immunity at the colorectal cancer invasive front. bioRxiv website. https://www.biorxiv.org/content/10.1101/743989v1.full. Published August 24, 2019. Accessed July 17, 2020.

28. Lindmo T, Boven E, Cuttitta F, Fedorko J, Bunn PA Jr. Determination of the immunoreactive fraction of radiolabeled monoclonal antibodies by linear extrapolation to binding at infinite antigen excess. J Immunol Methods. 1984;72:77-89.

29. Dorsch M, Urlaub D, Bonnemann V, Brode P, Sandusky M, Watzl C. Quantitative analysis of human NK cell reactivity using latex beads coated with defined amounts of antibodies. Eur J Immunol. 2020;50:656-665.

30. Vacca P, Cantoni C, Prato C, et al. Regulatory role of NKp44, NKp46, DNAM-1 and NKG2D receptors in the interaction between NK cells and trophoblast cells: evidence for divergent functional profiles of decidual versus peripheral NK cells. Int Immunol. 2008;20:1395-1405.

31. Tavri S, Jha P, Meier R, et al. Optical imaging of cellular immunotherapy against prostate cancer. Mol Imaging. 2009;8:15-26.

32. Lim YT, Cho MY, Noh YW, Chung JW, Chung BH. Near-infrared emitting fluorescent nanocrystals-labeled natural killer cells as a platform technology for the optical imaging of immunotherapeutic cells-based cancer therapy. Nanotechnology. 2009;20:475102.

33. Matera L, Galetto A, Bello M, et al. In vivo migration of labeled autologous natural killer cells to liver metastases in patients with colon carcinoma. $J$ Transl Med. 2006;4:49

34. Melder RJ, Brownell AL, Shoup TM, Brownell GL, Jain RK. Imaging of activated natural killer cells in mice by positron emission tomography: preferential uptake in tumors. Cancer Res. 1993;53:5867-5871.

35. Meier R, Piert M, Piontek G, et al. Tracking of $\left[{ }^{18} \mathrm{~F}\right]$ FDG-labeled natural killer cells to her2/neu-positive tumors. Nucl Med Biol. 2008;35:579-588.

36. Deri MA, Zeglis BM, Francesconi LC, Lewis JS. PET imaging with ${ }^{89} \mathrm{Zr}$ : from radiochemistry to the clinic. Nucl Med Biol. 2013;40:3-14.

37. Rice SL, Roney CA, Daumar P, Lewis JS. The next generation of positron emission tomography radiopharmaceuticals in oncology. Semin Nucl Med. 2011;41:265-282.

38. Miller JS, Rooney CM, Curtsinger J, et al. Expansion and homing of adoptively transferred human natural killer cells in immunodeficient mice varies with product preparation and in vivo cytokine administration: implications for clinical therapy. Biol Blood Marrow Transplant. 2014;20:1252-1257.

39. Cany J, van der Waart AB, Tordoir M, et al. Natural killer cells generated from cord blood hematopoietic progenitor cells efficiently target bone marrow-residing human leukemia cells in NOD/SCID/IL2Rg(null) mice. PLoS One. 2013;8:e64384.

40. Long EO, Kim HS, Liu D, Peterson ME, Rajagopalan S. Controlling natural killer cell responses: integration of signals for activation and inhibition. Annu Rev Immunol. 2013;31:227-258.

41. Gauthier L, Morel A, Anceriz N, et al. Multifunctional natural killer cell engagers targeting NKp46 trigger protective tumor immunity. Cell. 2019;177:17011713.e16. 